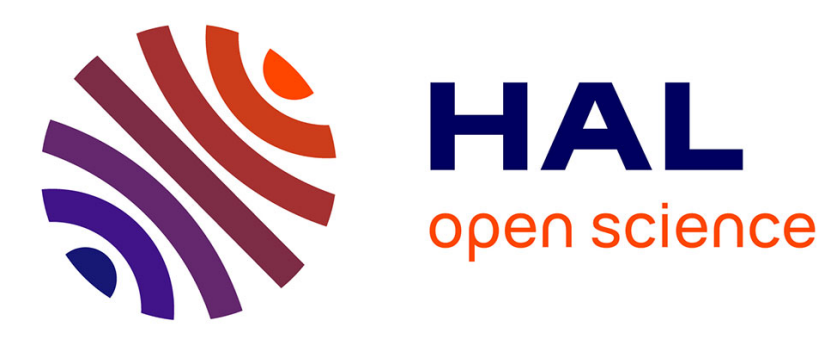

\title{
USP19 is a ubiquitin-specific protease regulated in rat skeletal muscle during catabolic states
}

Lydie Combaret, Olasunkanmi A. J. Adegoke, Nathalie Bedard, Vickie

Baracos, Didier Attaix, Simon S. Wing

\section{- To cite this version:}

Lydie Combaret, Olasunkanmi A. J. Adegoke, Nathalie Bedard, Vickie Baracos, Didier Attaix, et al.. USP19 is a ubiquitin-specific protease regulated in rat skeletal muscle during catabolic states. AJP - Endocrinology and Metabolism, 2005, 288 (4), pp.E693-E700. 10.1152/ajpendo.00281.2004. hal-02680332

\section{HAL Id: hal-02680332 \\ https: / hal.inrae.fr/hal-02680332}

Submitted on 31 May 2020

HAL is a multi-disciplinary open access archive for the deposit and dissemination of scientific research documents, whether they are published or not. The documents may come from teaching and research institutions in France or abroad, or from public or private research centers.
L'archive ouverte pluridisciplinaire HAL, est destinée au dépôt et à la diffusion de documents scientifiques de niveau recherche, publiés ou non, émanant des établissements d'enseignement et de recherche français ou étrangers, des laboratoires publics ou privés. 
Lydie Combaret, Olasunkanmi A. J. Adegoke, Nathalie Bedard, Vickie Baracos, Didier Attaix and Simon S. Wing

Am J Physiol Endocrinol Metab 288:693-700, 2005. First published Nov 23, 2004;

doi:10.1152/ajpendo.00281.2004

You might find this additional information useful...

This article cites 38 articles, 16 of which you can access free at:

http://ajpendo.physiology.org/cgi/content/full/288/4/E693\#BIBL

This article has been cited by 4 other HighWire hosted articles:

USP19-deubiquitinating enzyme regulates levels of major myofibrillar proteins in L6 muscle cells

P. Sundaram, Z. Pang, M. Miao, L. Yu and S. S. Wing

Am J Physiol Endocrinol Metab, December 1, 2009; 297 (6): E1283-E1290.

[Abstract] [Full Text] [PDF]

Fed-state clamp stimulates cellular mechanisms of muscle protein anabolism and modulates glucose disposal in normal men

O. A. J. Adegoke, S. Chevalier, J. A. Morais, R. Gougeon, S. R. Kimball, L. S. Jefferson, S. S.

Wing and E. B. Marliss

Am J Physiol Endocrinol Metab, January 1, 2009; 296 (1): E105-E113.

[Abstract] [Full Text] [PDF]

The biological mechanisms of cancer-related skeletal muscle wasting: the role of progressive resistance exercise.

S. Al-Majid and H. Waters

Biol Res Nurs, July 1, 2008; 10 (1): 7-20.

[Abstract] [PDF]

Mechanisms of glucocorticoid-induced myopathy

O Schakman, H Gilson and J P Thissen

J. Endocrinol., April 1, 2008; 197 (1): 1-10.

[Abstract] [Full Text] [PDF]

Updated information and services including high-resolution figures, can be found at:

http://ajpendo.physiology.org/cgi/content/full/288/4/E693

Additional material and information about AJP - Endocrinology and Metabolism can be found at: http://www.the-aps.org/publications/ajpendo

This information is current as of September 3, 2010 .

AJP - Endocrinology and Metabolism publishes results of original studies about endocrine and metabolic systems on any level of organization. It is published 12 times a year (monthly) by the American Physiological Society, 9650 Rockville Pike, Bethesda MD 20814-3991. Copyright @ 2005 by the American Physiological Society. ISSN: 0193-1849, ESSN: 1522-1555. Visit our website at http://www.the-aps.org/. 


\title{
USP19 is a ubiquitin-specific protease regulated in rat
}

\section{skeletal muscle during catabolic states}

\author{
Lydie Combaret, ${ }^{1,2}$ Olasunkanmi A. J. Adegoke, ${ }^{1}$ Nathalie Bedard, ${ }^{1}$ \\ Vickie Baracos, ${ }^{3}$ Didier Attaix, ${ }^{2}$ and Simon S. Wing ${ }^{1}$ \\ ${ }^{1}$ Polypeptide Laboratory, Department of Medicine, McGill University, Montreal, Quebec; \\ ${ }^{3}$ Department of Oncology, University of Alberta, Edmonton, Alberta, Canada; and ${ }^{2}$ Institut \\ National de la Recherche Agronomique, Nutrition and Protein Metabolism Unit, Ceyrat, France
}

Submitted 28 June 2004; accepted in final form 18 November 2004

Combaret, Lydie, Olasunkanmi A. J. Adegoke, Nathalie Bedard, Vickie Baracos, Didier Attaix, and Simon S. Wing. USP19 is a ubiquitin-specific protease regulated in rat skeletal muscle during catabolic states. Am J Physiol Endocrinol Metab 288: E693-E700, 2005. First published November 23, 2004; doi:10.1152/ajpendo.00281. 2004.- -Ubiquitin-dependent proteolysis is activated in skeletal muscle atrophying in response to various catabolic stimuli. Previous studies have demonstrated activation of ubiquitin conjugation. Because ubiquitination can also be regulated by deubiquitinating enzymes, we used degenerate oligonucleotides derived from conserved sequences in the ubiquitin-specific protease (UBP) family of deubiquitinating enzymes in RT-PCR with skeletal muscle RNA to amplify putative deubiquitinating enzymes. We identified USP19, a 150-kDa deubiquitinating enzyme that is widely expressed in various tissues including skeletal muscle. Expression of USP19 mRNA increased by $\sim 30-200 \%$ in rat skeletal muscle atrophying in response to fasting, streptozotocin-induced diabetes, dexamethasone treatment, and cancer. Increased mRNA levels during fasting returned to normal with refeeding, but 1 day later than the normalization of rates of proteolysis and coincided instead with recovery of muscle mass. Indeed, in all catabolic treatments, USP19 mRNA was inversely correlated with muscle mass and provided an index of muscle mass that may be useful in many pathological conditions, using small human muscle biopsies. The increased expression of this deubiquitinating enzyme under conditions of increased proteolysis suggests that it may play a role in regeneration of free ubiquitin either coincident with or after proteasome-mediated degradation of substrates. USP19 may also be involved in posttranslational processing of polyubiquitin produced de novo in response to induction of the polyubiquitin genes seen under these conditions. Deubiquitinating enzymes thus appear involved in muscle wasting and implicate a widening web of regulation of genes in the ubiquitin system in this process.

deubiquitinating enzyme; ubiquitin-proteasome-dependent proteolysis; muscle wasting; proteolysis

SKELETAL MUSCLE PLAYS A VITAL ROLE in locomotion and respiration and in the metabolic adaptation to stress by acting as a reserve of essential and nonessential amino acids. Sustained loss of skeletal muscle, as occurs in starvation and a number of wasting disorders, has a negative impact upon rehabilitation or survival of the organism. A precise knowledge of the mechanisms responsible for the mobilization of muscle proteins is therefore needed. The loss of skeletal muscle proteins results from a negative balance between rates of protein synthesis and protein breakdown. Accelerated protein breakdown in muscle

Address for reprint requests and other correspondence: S. S. Wing, Polypeptide Laboratory, Dept. of Medicine, McGill University, 3640 University St., Montreal, Quebec H3A 2B2, Canada (E-mail: simon.wing@mcgill.ca). wasting during catabolic states appears to reflect mainly the activation of the ubiquitin-proteasome proteolytic pathway (reviewed in Refs. 1, 22, 28). Therefore, a detailed analysis of the regulation of this pathway is important.

In this pathway, specific intracellular proteins become ubiquitinated and are thereby targeted for degradation (reviewed in Ref. 13). Covalent attachment of ubiquitin to cellular proteins occurs by formation of an isopeptide bond between the $\mathrm{COOH}$-terminal glycine residue of ubiquitin and the $\varepsilon$-amino group of a lysine residue of the target protein. This conjugation reaction requires ATP hydrolysis and the serial actions of at least three enzymes: the ubiquitin-activating enzyme (El), ubiquitin-conjugating enzymes (E2), and ubiquitin-protein ligases (E3). E3 enzymes possess substrate binding properties (reviewed in Ref. 32). Additional ubiquitins are typically successively ligated also via isopeptide bonds between the $\varepsilon$-amino group of $\mathrm{Lys}^{48}$ of one ubiquitin to the $\mathrm{COOH}$ terminus of the other to form branched polyubiquitin chains. Polyubiquitinated proteins are then recognized by the $26 \mathrm{~S}$ proteasome and degraded in an ATP-dependent manner.

Although protein ubiquitination is a reversible process, attention has been paid primarily to characterizing the enzymes responsible for conjugation of ubiquitin to proteins. However, deconjugation of ubiquitin appears also to play important roles in regulating ubiquitin-dependent pathways (reviewed in Refs. 18, 38). Deubiquitinating enzymes may remove ubiquitin from substrates, rescuing them from degradation $(6,10,25,30)$. They may also act concomitantly or after proteasome-mediated degradation of the substrate to recycle ubiquitin from the polyubiquitin chain. Indeed, several deubiquitinating enzymes, UBP6 (24), UCH37 (19), and Rpn11 (36), are actually associated with the $26 \mathrm{~S}$ proteasome. Furthermore, ubiquitin is synthesized as ubiquitin-ribosomal fusion proteins or as a linear polyubiquitin fusion arranged in tandem (29). Thus some deubiquitinating enzymes are involved in the generation of free ubiquitin from these polyproteins.

Many genes encoding deubiquitinating enzymes have recently been identified from different organisms. These deubiquitinating enzymes fall into two major families, both thiol proteases: the ubiquitin $\mathrm{COOH}$-terminal hydrolases $(\mathrm{UCH})$, which seem to mainly play a role in elimination of small adducts from ubiquitin and in generation of free monomeric ubiquitin from its precursors, and the ubiquitin-specific processing proteases (UBPs/USPs), which are involved in disas-

The costs of publication of this article were defrayed in part by the payment of page charges. The article must therefore be hereby marked "advertisement" in accordance with 18 U.S.C. Section 1734 solely to indicate this fact. 
sembling the polyubiquitin degradation signal and/or in editing the ubiquitination state of proteins (reviewed in Refs. 18, 38). More than 90 putative deubiquitinating enzymes have been identified by the human genome sequencing project, making them one of the largest family of enzymes in the ubiquitin system (8). In addition, there are recent reports describing novel deubiquitinating enzymes that do not belong to either of the two major classes. Rpn11, a subunit of the lid of the 19S cap of the 26S proteasome, has an essential deubiquitinating activity and appears to be a $\mathrm{Zn}^{2+}$ metalloproteinase (36). An enzyme bearing an otubain motif has also been shown to have deubiquitinating activity (3). Although deubiquitinating enzymes have been implicated in a number of biologically important processes, including cell growth and differentiation, development, oncogenesis, neuronal diseases, and genome integrity (reviewed in Refs. 18, 38), the physiological functions of most of the enzymes remain unknown.

Previous studies have shown increased levels of ubiquitination of muscle proteins in several catabolic conditions $(9,23$, 34,39 ), suggesting a simple model in which increased flux through the pathway arises from increased formation and presentation of ubiquitinated proteins to the proteasome. In support of this, there is increased expression of genes in the conjugation pathway, such as the polyubiquitin genes and some ubiquitin conjugating enzymes (reviewed in Ref. 16), as well as some ubiquitin protein ligases $(5,15,26,27,40)$. However, the ubiquitin system contains a large number of genes, and the regulation of these genes is likely to be complex. Indeed, a recent analysis using gene arrays has indicated that a large number of ubiquitin system genes are regulated in atrophying muscles (21).

Deubiquitinating enzymes could play important roles in this degradative process. Suppression of some of these enzymes could increase the ubiquitination state of proteins and therefore their degradation. Some protein substrates actually appear to be bound to both their ubiquitin protein ligases and deubiquitinating enzymes (25), indicating a tight regulation of ubiquitination status of the protein. Alternatively, activation of some of these enzymes could be important in maintaining free ubiquitin levels during increased flux through this pathway. For example, several deubiquitinating enzymes have been implicated in the depolymerization of the polyubiquitin chain after commitment of the substrate protein for degradation (reviewed in Ref. 38). Some of these enzymes are components of the $19 \mathrm{~S}$ regulatory complex, indicating a tight coupling between the degradative step and the deubiquitination process. Because of the important potential roles of deubiquitinating enzymes, we began to identify them in skeletal muscle. Here, we describe the cloning and characterization of USP19, a deubiquitinating enzyme that is expressed in muscle and induced during catabolic conditions.

\section{MATERIALS AND METHODS}

Cloning of cDNA encoding USP19. RT-PCR was used to identify the deubiquitinating enzyme(s) expressed in rat skeletal muscle. cDNA was synthesized from total rat muscle RNA $(2.5 \mu \mathrm{g})$ in a $20-\mu \mathrm{l}$ reaction, using RT (GIBCO-BRL Superscript Preamp kit) according to the manufacturer's procedure with oligo(dT) as a primer. The cDNA $(5 \mu \mathrm{l})$ was then used as a template in a PCR reaction containing, as primers, degenerate oligonucleotides corresponding to the conserved cysteine box (5'-GGIAAT/CACITGT/CTA/TT/CC/A/
TTGAA-3') and to the aspartic box (5'-TTIAA/GA/GTCT/CTCA/ GTGIAA/GNCCA/GTC-3') of UBPs (37). Annealing was carried out at $45^{\circ} \mathrm{C}$ and extension at $72^{\circ} \mathrm{C}$ for $3 \mathrm{~min}$, and 35 cycles were performed. The amplified DNA fragments were subcloned into the pGEM-T vector (Promega) and sequenced with the dideoxy chain termination method and T7 polymerase (Pharmacia). Because the predicted protein sequence showed marked similarity to other motifs conserved in UBPs (37), the PCR-amplified DNA fragment from clone 1 was labeled with ${ }^{32} \mathrm{P}$ and used as a probe to screen a rat testis cDNA library in the $\lambda$ zapII vector (Stratagene). An aliquot containing $10^{6}$ recombinants was screened by transfer of plaques to nylon membranes and hybridization with the probe. Positive phage clones were purified, and the pBluescript phagemid containing the insert was excised from the phage according to the supplier's instructions. The insert in the plasmid was sequenced, and overlapping clones were isolated. To identify the initiator methionine, the rat testis cDNA library was screened several times using ${ }^{32} \mathrm{P}$-labeled probes corresponding to the $5^{\prime}$-terminal residues of the last open reading frame of DNA sequence obtained. In addition, the $5^{\prime}$-RACE method (12) was used to identify an additional sequence at the $5^{\prime}$-end. The final sequence was deposited in GenBank under accession no. (AC) AY605065.

Catabolic conditions. The animal facilities and protocols were approved by the local institutional animal care committees. Animals were housed under controlled environmental conditions (temperature $22^{\circ} \mathrm{C}, 12: 12$-h light-dark cycle with lights on at 0800). They were fed ad libitum with a commercial laboratory chow before the experiments were performed and had free access to water.

In fasting experiments, male Wistar rats (Charles River Laboratories, Lyon, France, or St. Constant, Quebec) were allocated to fed (control) and 1- or 2-day-fasted groups. Two other groups that were fasted and then refed for 1 or 2 days were also included in some studies. All rats had free access to water. At the end of the experiment, rats weighed $70-90 \mathrm{~g}$.

To induce diabetes, male Wistar rats were fasted overnight. The next morning at 0900 , one-half of the animals were given a single tail vein injection of streptozotocin (ICN, Orsay, France; $125 \mathrm{mg} / \mathrm{kg}$ prepared fresh in $0.1 \mathrm{M}$ citrate buffer, $\mathrm{pH} 4.5)$. These rats were refed ad libitum immediately after the injection, and the amount of food eaten by the streptozotocin-treated rats was measured. Vehicle-injected control rats were pair fed (PF) the same amount of food. Animals were fasted overnight before death at 3, 5, or 10 days after injection of streptozotocin or vehicle.

Glucocorticoid-treated rats (Iffa-Credo, Lyon, France) were 8 mo old. They were randomly divided into a control and a dexamethasonetreated group. Dexamethasone (a synthetic glucocorticoid analog) was given daily at 0900 in the drinking water for 6 days. The dexamethasone concentration was adjusted every day on the basis of the amount of water that the animals drank the preceding day. Rats received $540 \pm 92 \mu \mathrm{g}$ dexamethasone $\cdot \mathrm{kg}$ body $\mathrm{wt}^{-1} \cdot$ day $^{-1}$ to induce significant muscle atrophy (11). Because administration of dexamethasone decreased food intake, the control group was PF to the dexamethasone group.

Experimental procedures for the implantation of the Yoshida hepatoma and sarcoma tumors were as described previously (4, 33). Gastrocnemius and tibialis anterior muscles were excised from rats bearing either Yoshida hepatoma tumors for 6 days or Yoshida sarcoma tumors for 9 days. For each cancer condition, control rats were PF to the tumor-bearing animals. In all of the above studies, the muscles indicated in the figures were isolated, rapidly frozen in liquid nitrogen, and then stored at $-80^{\circ} \mathrm{C}$ until used for further analysis.

Northern hybridization. RNA was prepared from rat tissues as described $(2,7)$. RNA blotting was performed by resolving 10-20 $\mu \mathrm{g}$ of RNA on $1 \%$ agarose gels containing formaldehyde, transferring the products to nylon membranes, and cross-linking them with UV light. After a 1-h prehybridization, the membranes were hybridized overnight at $65^{\circ} \mathrm{C}$ with a ${ }^{32} \mathrm{P}$-labeled, PCR-amplified fragment corre- 
A

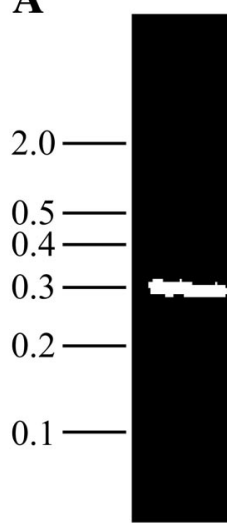

C

GGGCACACCTGCTTCATGAATAGTGTCATT CAGTCTCTGTCCAACACTCGGGAGCTTCGT GACTTCTTCCACGACCGATCCTTTGAGGCT GAGATTAACTACAATAACCCATTGGGGACT GGTGGGCGTCTGGCTATTGGCTTCGCTGTG CTGCTCCGGGCCCTGTGGAAGGGCACTCAC CAAGCCTTTCAACCCTCCAAGCTAAAGGCC ATTGTAGCAAGCAAGGCCAGCCAGTTTACA GGCTACGCACAGCATGATGCCCAAGAGTTC ATGGCTTTCTTGTTGGATGGGCTGCATGAA GACCTGAA
30

60 90 120 150 180 210 240 270 300 308
Fig. 1. PCR amplification of a rat DNA fragment with sequence similarity to the ubiquitin-specific protease (UBP) family of enzymes. $A$ : rat muscle RNA was reverse transcribed, and the cDNA was used as template in a PCR with degenerate oligonucleotides derived from 2 conserved regions, the cysteine box and the aspartic box. The product was electrophoresed on a $1 \%$ agarose gel containing ethidium bromide and visualized with a UV transilluminator. $B$ : aliquots $(10 \mu \mathrm{g})$ of pools of RNA isolated from the extensor digitorum longus (EDL) skeletal muscle of fed or starved animals were electrophoresed on a $1 \%$ agarose gel and transferred to a nylon membrane. After hybridization with the ${ }^{32} \mathrm{P}$-labeled clone 1 , the membranes were washed and autoradiographed. $C$ : sequence of the $\sim 300$-bp DNA fragment corresponding to clone 1 , the expression of which was shown to be increased in atrophying muscles in $B$.

sponding to a region between the cysteine box and the aspartic box of USP19 using a single reverse primer (5'-TTGAGGTCTTCGTGGAGACCGTC- $\left.3^{\prime}\right)$. Membranes were then washed at the same temperature twice in $2 \times$ SSC and $0.1 \%$ SDS for $20 \mathrm{~min}$ and subjected to autoradiography. The signals were quantified by densitometry. Autoradiographic signals were normalized using the corresponding $18 \mathrm{~S}$ rRNA signals to correct for variations in RNA loading.

Statistical analyses. Comparison of mean levels of expression of USP19 between various conditions was by one-way ANOVA. The relationship between USP19 expression and muscle mass in several catabolic states was assessed by linear regression. These analyses were performed with the SAS Statview package (Statview for Windows version 5.0; SAS Institute, Cary, NC). Statistically significant differences were defined at $P<0.05$.

\section{RESULTS}

Identification of a cDNA with sequence similarity to the UBP family of deubiquitinating enzymes. To isolate deubiquitinating enzyme(s) belonging to the UBP family that might be expressed in rat skeletal muscle, oligonucleotides derived from protein sequences conserved in the UBP family corresponding to the cysteine and the aspartyl boxes were used in PCRs with rat skeletal muscle cDNA obtained by reverse transcription as template. Although the oligonucleotides were made degenerate to amplify as many potential UBPs as possible, a single fragment of $\sim 300 \mathrm{bp}$ was amplified (Fig. $1 A$ ). However, when cloned and sequenced, it was found to contain four different nucleotide sequences. Analysis of the sequences internal to the primers suggested strongly that these were partial sequences of UBP enzymes. Search of gene databases for similarity using the Basic Local Alignment Search Tool (BLAST) program indicated that clone 1 was the rat ortholog of human USP19 (AC O94966). Clones 2 and 3 appeared to be related, respectively, to UBP45 (AC Q9R084) and UBP109 (AC Q9R085). Finally, clone 4 is the rat ortholog of UBP6 (AC P35125) that, in humans, has been shown to be associated with the proteasome (24). Initial studies showed that the 300-bp clone 1 probe recognized a single transcript at $4.4 \mathrm{~kb}$ that was not detected by the probes for clones 2, 3, and 4. In addition, clone 1 was regulated in response to atrophy induced by fasting (Fig. 1B). Therefore, it was decided to pursue a detailed characterization of this UBP.

Tissue expression of the putative UBP enzyme isolated from rat skeletal muscle. To determine which tissues express this UBP, the labeled clone 1 DNA fragment was used as a probe on an RNA blot prepared with total RNA from various rat tissues (Fig. 2). A unique transcript of $4.4 \mathrm{~kb}$ was detected. High levels of expression were seen in the testis, heart, kidney, and glycolytic extensor digitorum longus (EDL) muscle. Low levels of expression were detectable in all other tissues screened.

Cloning of full-length cDNA encoding this putative UBP enzyme. Because this work was initiated before the availability of large rodent sequence databases, we determined the fulllength sequence by using the PCR-amplified fragment as a probe to screen a cDNA library. A testis cDNA library was used because of the high level of expression in this tissue. From $10^{6}$ recombinants screened, $\sim 45$ positive clones were identified. Subsequent screening and complete sequencing revealed that these clones overlapped to give a large cDNA with a reading frame that was still open at the $5^{\prime}$-end. A second screening of the cDNA library was done using, as a probe, a DNA fragment corresponding to the distal $5^{\prime}$-end of the known sequence. A third cDNA fragment was also isolated, se-

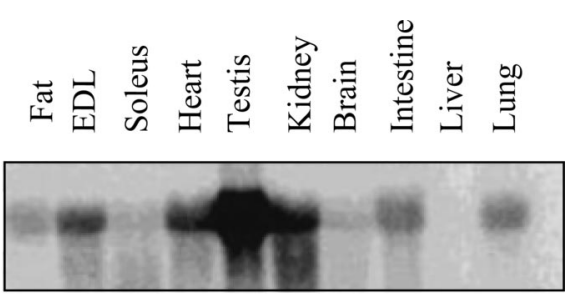

$18 \mathrm{~S}$

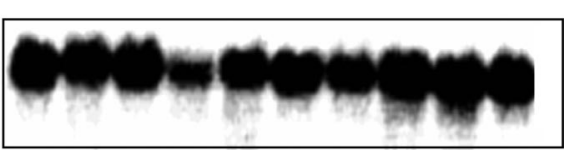

Fig. 2. RNA blot of various rat tissues with clone 1. Aliquots $(10 \mu \mathrm{g})$ of pools of RNA from the indicated tissues of 5 animals were electrophoresed on a $1 \%$ agarose gel and transferred to a nylon membrane. After hybridization with the ${ }^{32} \mathrm{P}$-labeled clone 1 or $18 \mathrm{~S}$ rRNA probe, the membrane was washed and autoradiographed. 
quenced, and overlapped with the previous cDNA sequence. This, combined with 5'-RACE analysis, yielded a final open reading frame of 4,071 bp. When translated, this open reading frame encoded a protein of $\sim 150 \mathrm{kDa}$ (Fig. 3) with a predicted
pI of 6.6. The analysis of that predicted protein sequence revealed that this UBP shows $81 \%$ amino acid identity and $85 \%$ similarity to the human USP19 protein and $95 \%$ identity and $98 \%$ similarity to the mouse ortholog. Aside from the
Fig. 3. A: predicted protein sequence for USP19 in rat skeletal muscle. Sequences conserved in the UBP family of deubiquitinating enzymes are underlined. The sequences in bold identify the critical cysteine (residues 537-554) and histidyl (residues 1187-1250) boxes. $B$ : alignment of USP19 cysteine and histidyl boxes with those from other representative deubiquitinating enzymes.

\begin{abstract}
A MSAGTSATGPRRGPPGLEEATSKKKQKDRANQESKDGDPRRVSMPRKEPTKDELLLDWRQ SSDKVVVKLRVGTGPICLEEVDAAFTDTDCVVRLPDGRQWGGVFEAKIQSSCTKVOTRKG GLLQLALPKKVPLLTWPSLLKKPLGTQELVPGLRCQENGQELSP IALEPGSEPRRAKQEA RNQKRAQGRGEVGSGASPGAQAGPSAKRAVHLCRGPEGEGSMDGPGPQGDAPSFLSDSAT QVEAEEQLHVPPVNPQTSLLGSEKNLALLTVEKTVSPRSDSVSPVMIRNRDPEKDDHEKE EMAVGADPAALADEPESMVNLAFVKNDSYEKGPDSVVVHVYVKESRRDTSRVLEREQDFT LIFQTRDGNFLRLHPGCGPHTIFRWQVKLRNLIEPEQCTECFTASRIDICLRKRQSQRWG GLEAPATRVGGAKVAVPTGPTPLDSTPPGGGPLPLTGQEEARAVEKEKPKARSEDSGLDG VVARTPLEHVTPKPEPHLASPKPTCMVPPMPHSPVSGDSVEEDEEEEKKVCLPGETGLVN LGHTCFMNSVIQSLSNTRELRDFFHDRSFEAEINYNNPLGTGGRIAIGEAVLLRALWKGT HQAFQPSKLKAIVASKASQFTGYAQHDAQE FMAFLLDGLHEDLNRIQNKPYTETVDSDGR PDEVVAEEAWQRHKMRNDSF IVDLFQGQYKSKLVCPVCAKVSITEDPFLYLPVPLPQKQK VLPIYYFAREPHSKPIKFLVSVSKENSSASEVLESLSQSVHVKPESLRLAEVIKNRFHRV FLPSHSLDAVSPTDVLLCFELLSPELAKERVVVLEVQQRPQVPS I P S SCAACQRKQQSE DEKLKRCTRCYRVGYCNQFCQKTHWPDHKGLCRPENIGYPFLVSVPASRLTYARLAQLLE GYARYSVSVFQPPEQPGRMALESQSPGCTTLISTSSLEAGDSEREP IQPSELQLVTPVAE GDTGAHRMWPPADRGPVPSTSGISSEMLASGPMEGCSLLAGERVSRPEAAVPGYQHSRES 1020 VSAHTPQFEIYKIDASSREQRLEDKGDTPLELGDDCSLALVWRNNERLQEFVLVASKELE 1080 CAEDPGSAGEAARAGHFTLDQCLNLFTRPEVLAPEEAWYCPQCKQHREASKQLLLWRLPN 1140 VLIVQLKRESERSEIWRDKINDLVEFPVRNLDLSKFCIGQKEEQLPSYDLYAVINHYGGM 1200 IGGHYTACARLPSDRS SQRSDVGWRLFDDSTVTTVDESQVVTRYAYVLFYRRRNSPVERP 1260 PRAAHAEHHPDLGLAAEAAASQASRIWQELEAEEEMVPEGPGPLGPWGPQDWVGPPPRGP 1320 TTSDEGCLRYFVLGTVAALVALVLNVFYPLVSQSRWR
\end{abstract}

\section{B}

Rat USP 19

Unknown mouso prot

HUMAN USP 19

Mouse USP 15

Rat UB'? $10 \mathrm{~b}$

USSP 11

Mouse USP 69

Human USP 33

PVIJT, interacting DUB?

Mouse Riken cDNA4930511011 Yeast USP 8

Rat USP 19

Unknown mouse prot

Gumar USP 79

Mouse USP 15

Rat UBP 105

USP 11.

Mouse USP 69

Human USP 33

PVHL interacting DUB2

Mouse Riken CDNA1930b11011.

Yeast USP 8

Rat USP 19

Jnknown mouse prot

Human USP 19

Mouse USP 15

Rat UBP 105

USP 11

Mouse USP 69

humar UST 33

PVHL inleracting DUB2

Mouse Riken CDNA1930b11011.

Yeast UCH 8
CYS BOX

LPGETGLVNLGNTCEMNSVIQSLSNTRELRDEEHDRSFEAE INYNNPLGT 581 I.PGFTGT,VNT,GNTCFMNSVTQSI,SNTRF,T,RDFFHDRSFF.AF,TNYNNPT,GT 584 LFGETGLVNLGNTCEMNSVIQSLSNTRELRDFEHDRSFEAEINYNNPLGT 595 -PGLCGLSNLGNTCFMNSAIQCLSNIPFLIEYELNDKYQEELNEDNPLGM 334

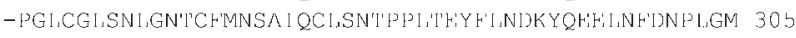
NGGDRGLINLGNTCELNSSLQCLSKILRF TNYFLSGTFWDHINYCNPVGO 210 -QGLAGLRNLGNTCFMNS I LQCLSNTRELRDYCLQRLYMRDLGHTS--SA 324 -RGLTGLKNIGNTCYMNAALQALSNCPPLTQFELDCGGLART------DK 224

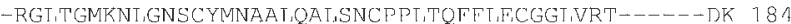
-QGVTGLRNLGNTCYMNA I LQCLCSVSFLVEYELSGKYITALK-----KD 85 -DGLSGL INMGSTCEMSSI LQCLIHNEYF IRHSMSQIHSNNCKVRSPDKC 182

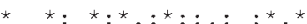

$$
\text { His Domain }
$$

GQ-------KEEQLPSYDLYAVINHYGGMIGGHYTACARLPSDRSSQRS 1220 GQ-------KEEQLPSYDLYAVINHYGGMIGGHYTACARLPNDRSSQRS 1223 GQ------KFFQT,PSYDT,YAVT,NIYYGGMT GGIYYACART,PNDRSSORS 1231 N--_--_--PNAGPCRYNLIAVSNHYGGMGGGHYTAFAKNKDDGK---- 903 N-------PNAGPCRYNLIAVSNHYGGMGGGHYTAFAKNKDDGK---- 874

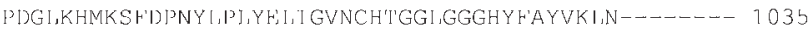
- ENTNIIAVYNLYAVSNIISCTTMGGIYYTAYCRSPVTGE--_- 583 KD--------SPAQIVTYDLLSVICHHGTASSGHYIAYCRNNINNNL---- 685 KE-------CTSQVITYDLLSVICHHGTAGSGHYIAYCONVINGQ---- 657 P-_--_--_VFRKHPMYNT,CAVVNHFGDT,DGGHYTAFCKNSVTQA---- 333 TKEKDKHSENGKVPDII YELIGIVSHKGTVNEGHY IAFCKISGGQ----- 438 * : . : ** **** :

DVGWRLFDDSTVTTVDESOVVTRYAYVLFYRRRNSPVERPPR----AAII 1265 DVGWRLFDDSTVTTVDESOVVTRYAYVLFYRRRNSPVERPPR-----ASH 1268 DVGWRLEDDSTVTIVDESQVVTRYAYVLFYRRRNSPVERPPR-----AGH 1279 - - WYYFDDSSVSTASFDQIVSKAAYVI,FYQRQDTFSGTGFF-_-_-DT,D 945 --WYYFDDSSVSSASEDQIVSKAAYVLFYQRQDTFSGTGFF----DLD 916 -GQWYNENDTYVTTINESQINTKNAYLLFYQLHTYKNEKFTD-------- 1076

-- WHTENDSSVTPMSSSOVRTSDAYLLFYELASPPSRM---------- 619

-- WYTFDDQSVTEVSFSTVQNAFAYVI, FYRKSSFFAOKFRRRT SNTTINT 1/3? -WYEFDDQYVTEVHETVVQNVEAYVLFYRKSSEEAMRERQDVVSLAAM 704 ---WYSEDDTRVSEIPDTSVOTATAYLIFYSCOPFS IPAOKR-------- 372 ---WEKFNDSMVSSISQEEVLKEQAYLLFYTIRQVN-------------- 471 * *** ** 
cysteine and aspartyl boxes, other motifs conserved in UBPs/ USPs (37) were also found (Fig. 3A). The cysteine and histidine boxes were similar to those found in many other members of the UBP/USP family (Fig. 3B).

Expression of USP19 mRNA in various conditions of atrophying skeletal muscle. To explore whether our initial observations of induction of expression upon fasting were common to other conditions of muscle wasting, we examined the levels of expression in various catabolic disorders where rates of protein degradation are increased and the ubiquitin-proteasome system is activated. USP19 mRNA levels increased by $\sim 50 \%$ in skeletal muscle from animals starved for $48 \mathrm{~h}$. The increased expression reverted to normal with refeeding (see Fig. $4 B$ ). However, this return to baseline occurred only on day 2 of refeeding, which was 1 day after the normalization of rates of protein breakdown (17) but was simultaneous to the recovery of muscle mass, which increased to levels similar to those of fed controls on day 2 (Fig. 4A). We examined whether the response to fasting was also seen in other tissues. No significant changes were seen in liver, kidney, and testis upon fasting (data not shown). By analyzing larger amounts of mRNA, USP19 mRNA expression could be reliably detected in soleus. Upon 2 days of fasting, the level of expression did increase but only by $25 \%$ (data not shown). The lower response in soleus than in EDL is consistent with a more pronounced catabolic response in fast-twitch compared with slow-twitch muscles.

Because the catabolic response to fasting is hormonally regulated, we examined the expression of USP19 after treatment with streptozotocin (which induces an insulinopenic form of diabetes) or dexamethasone (a glucocorticoid analog) in rats. After insulin deprivation, EDL muscle atrophies by 25 and $55 \%$ in rats treated with streptozotocin for 3 and 5 days, respectively, compared with $\mathrm{PF}$ animals (Fig. $5 A$ ). In these muscles, USP19 mRNA levels increased at 3 and 5 days after streptozotocin treatment by 61 and $213 \%$, respectively, compared with PF controls (Fig. 5B). Ten days after streptozotocin injection, muscle mass was similar to that at 5 days (Fig. 5A). Consistent with this decrease in the rate of atrophy, USP19 mRNA levels at 10 days were no longer significantly different from their PF controls (Fig. 5B). After dexamethasone treatment for 6 days in adult animals, epitrochlearis muscle mass decreased by $27 \%$ compared with that observed in PF controls (Fig. 6A). In these muscles, USP19 mRNA levels were elevated by $37 \%$ (Fig. $6 B$ ). The bands in the blot shown in Fig. $6 B$ did not migrate exactly at the same size. However, UV illumination of the corresponding agarose gel separation showed that there was a similar discrepancy in the migration of the $18 \mathrm{~S}$ and $28 \mathrm{~S}$ rRNA bands between the two lanes, indicating that this difference is simply an electrophoretic artifact.

Because cancer is an important common cause of muscle wasting (35), we also investigated the expression of USP19 in two rodent tumor-bearing conditions. Rats bearing the Yoshida hepatoma YAH130 (4) or the Yoshida sarcoma (33) exhibited a skeletal muscle atrophy of $\sim 20 \%$ (Fig. 7, $A$ and $D$ ), associated with an increase in USP19 mRNA levels of 124 and $133 \%$, respectively (Fig. 7, $B$ and $E$ ). In Yoshida sarcomabearing animals, it is possible to inhibit the increase in proteasome-dependent proteolysis in skeletal muscle by treatment with HWA448, a xanthine derivative that inhibits transcription of the TNF- $\alpha$ gene (9). Therefore, we examined the effect of such treatment on USP19 mRNA levels. Interestingly, USP19
A
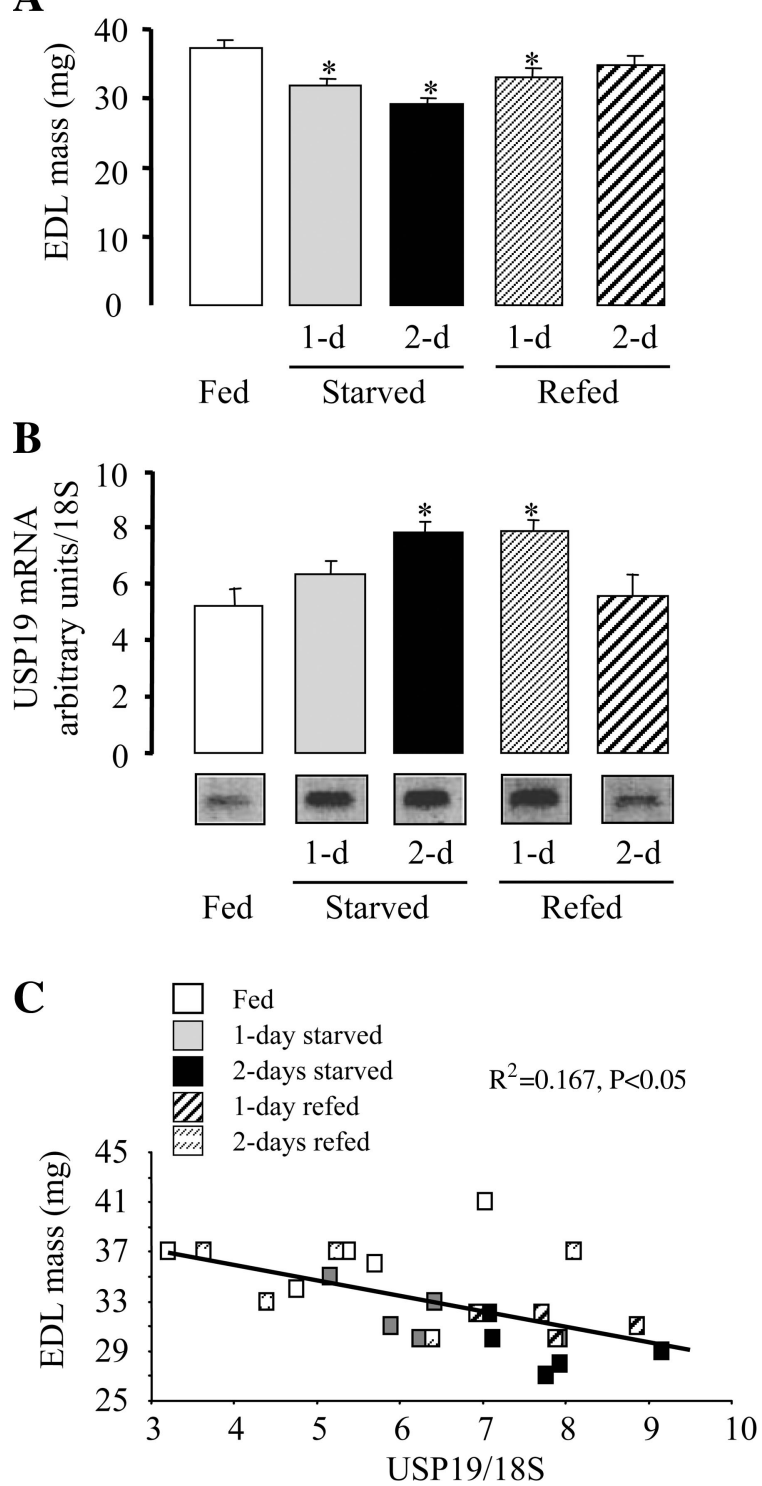

Fig. 4. Muscle mass (A) and USP19 mRNA levels $(B)$ of rat EDL skeletal muscle after 24 or $48 \mathrm{~h}$ of starvation and refeeding for 1 or 2 days. Twenty micrograms of total RNA were electrophoresed on a $1 \%$ agarose gel and transferred to a nylon membrane. After hybridization with the USP19 probe, the membrane was washed and autoradiographed. Signals were quantified and normalized using the corresponding signal from an $18 \mathrm{~S}$ rRNA probe to correct for uneven loading. Data are means \pm SE for 5 rats and are expressed as arbitrary units. Representative Northern blots are also shown. Statistical differences were assessed with ANOVA. ${ }^{*} P<0.05$ vs. fed rats. $C$ : there is a negative correlation of muscle mass with USP19 mRNA expression. $P<0.05$; $r^{2}=0.167$

mRNA level remained high (Fig. 7E). However, muscle wasting in the tumor-bearing rats was not totally prevented by HWA448, since EDL muscle mass from treated rats was still low (Fig. 7D).

Because the responses of USP19 mRNA levels to refeeding and to HWA448 treatment suggested that these levels correlated more closely with mean muscle mass than with the rates of proteolysis, we tested this association more carefully by applying linear regression analysis to all the samples that we studied (Figs. 4-7). Indeed, we observed statistically signifi- 
A

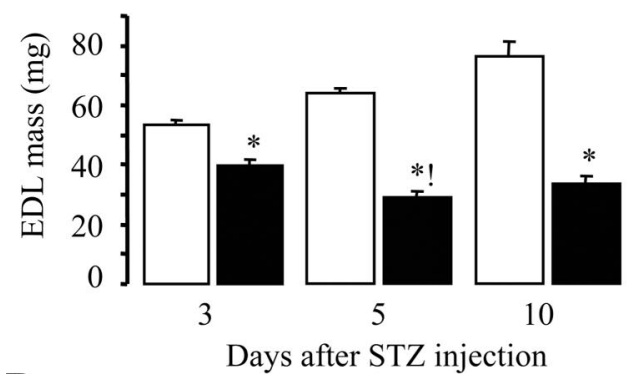

B

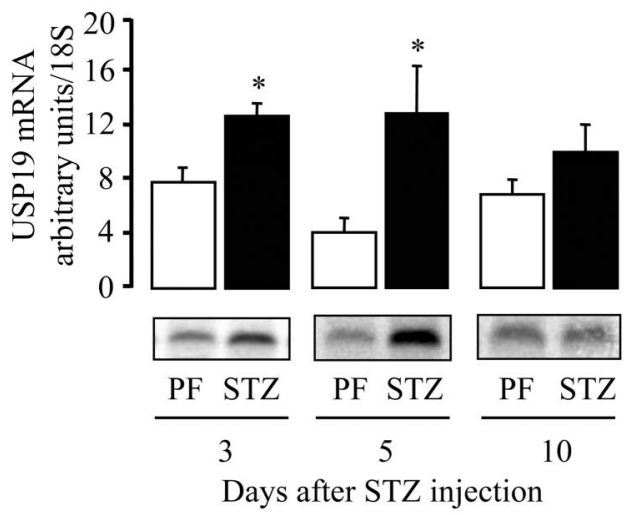

C

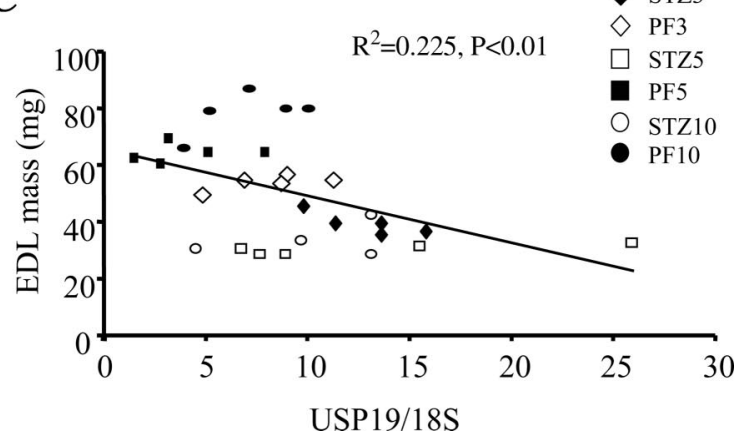

Fig. 5. Muscle mass $(A)$ and USP19 mRNA levels $(B)$ of rat EDL skeletal muscle isolated 3,5, and 10 days after streptozotocin (STZ) injection. Twenty micrograms of total RNA were electrophoresed on a $1 \%$ agarose gel and transferred to a nylon membrane. After hybridization with the USP19 probe, the membrane was washed and autoradiographed. Signals were quantified and normalized using the corresponding $18 \mathrm{~S}$ rRNA signals. Data are means $\pm \mathrm{SE}$ for 5 rats and are expressed as arbitrary units. Representative Northern blots are also shown. Statistical differences were assessed with ANOVA. $* P<0.05$ vs. pair-fed $(\mathrm{PF})$ rats. $! P<0.05$ vs. 3 -day streptozotocin-treated rats. $C$ : there is a negative correlation of muscle mass with USP19 mRNA expression. $P<$ $0.01 ; r^{2}=0.225$.

cant correlations between muscle mass and USP19 mRNA levels in all of the catabolic conditions that we studied.

\section{DISCUSSION}

Previous studies have clearly demonstrated that the process of conjugation of ubiquitin to proteins is highly regulated in atrophying skeletal muscles. Numerous studies have demonstrated increased expression of genes encoding polyubiquitin and the E2 $14 \mathrm{k}$ ubiquitin conjugating enzyme (reviewed in Ref. 16), and, more recently, there has been evidence of increased expression of two muscle-specific ubiquitin protein ligases,
MuRF1 and atrogin-1 (MAFbx), in response to various catabolic conditions (reviewed in Ref. 20).

Little is known about the regulation of deubiquitinating enzymes during muscle wasting despite the large family of such enzymes. Here, we report our early exploration of this area by using RT-PCR analysis of mRNA to identify muscle deubiquitinating enzymes. Such a search is presently rendered much simpler by the availability of ever larger expressed sequence tag databases and gene arrays containing more complete coverage of the genome. We have found that expression of the USP19 gene is increased after muscle wasting in response to a wide range of catabolic conditions. Although we established this induction at the mRNA level, we were unable to confirm this at the protein level, because expression levels of USP19 protein appeared to be very low in skeletal muscle tissue and not reliably detected by immunoblotting. The USP19 enzyme may play an important role in recycling ubiquitin concomitant with or after proteasome-mediated degrada-

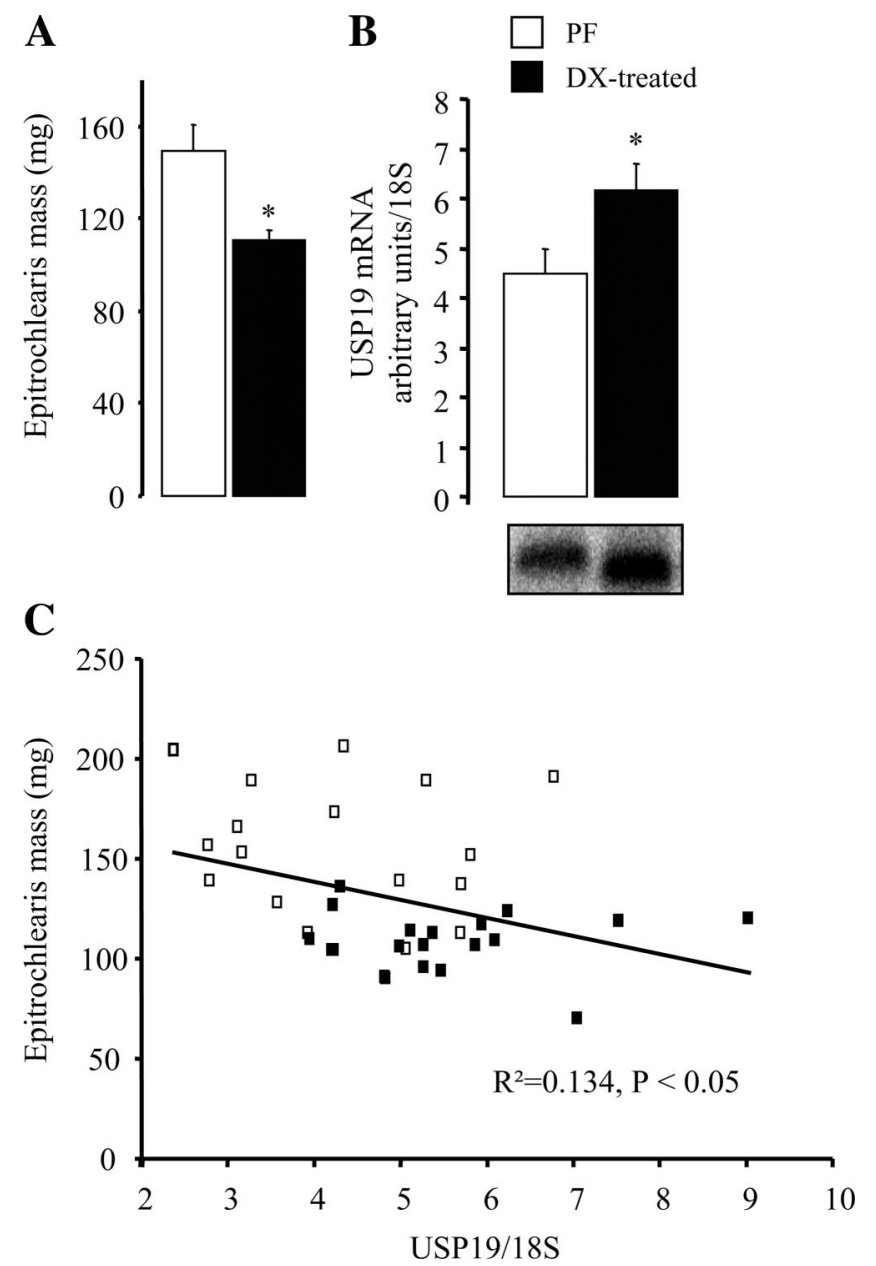

Fig. 6. Muscle mass $(A)$ and USP19 mRNA levels $(B)$ of rat epitrochlearis skeletal muscle from rats treated with dexamethasone for 6 days or from PF controls. Twenty micrograms of total RNA were electrophoresed on a $1 \%$ agarose gel and transferred to a nylon membrane. After hybridization with the USP19 probe, the membrane was washed and autoradiographed. Signals were quantified and normalized using the corresponding 18S rRNA signals. Data are means $\pm \mathrm{SE}$ for 8 rats and are expressed as arbitrary units. Representative Northern blots are also shown. Statistical differences were assessed with ANOVA. $* P<0.05$ vs. PF rats. $C$ : there is a negative correlation of muscle mass with USP19 mRNA expression. 
A

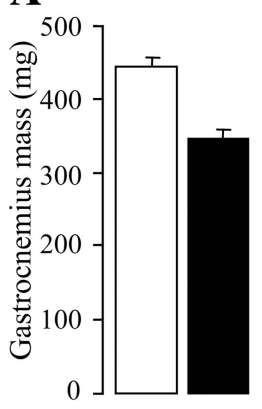

D $\square$ тF

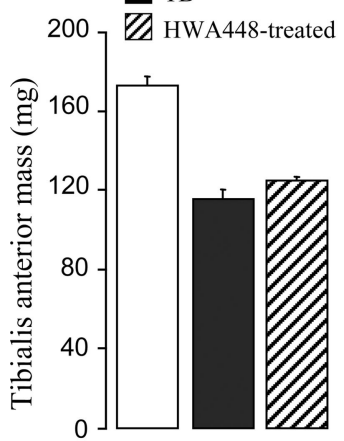

B

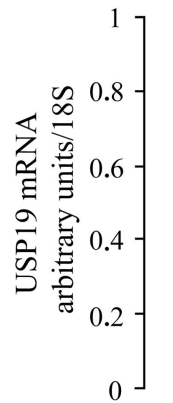

$\mathbf{E}$
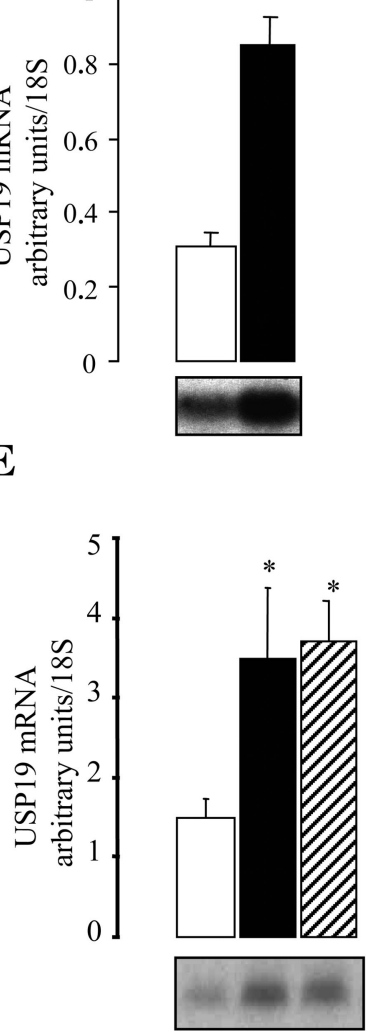

C

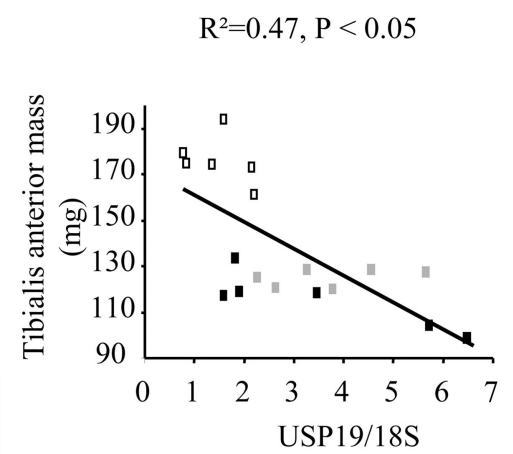

$\mathrm{R}^{2}=0.69, \mathrm{P}<0.05$

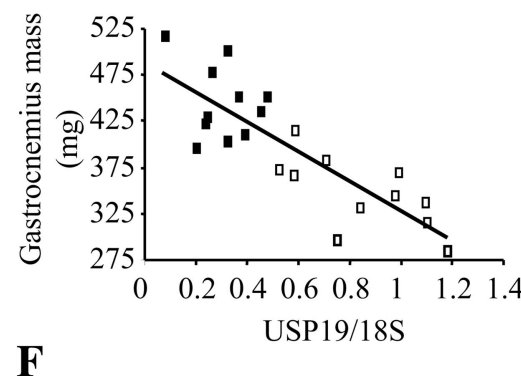

Fig. 7. Muscle mass ( $A$ and $D)$ and USP19 mRNA levels ( $B$ and $E$ ) of rat gastrocnemius or tibialis anterior skeletal muscles from Yoshida hepatoma $(A-C)$ - or Yoshida sarcoma $(D-F)$-bearing rats, respectively. Twenty micrograms of total RNA were electrophoresed on a $1 \%$ agarose gel and transferred to a nylon membrane. After hybridization with the USP19 probe, the membrane was washed and autoradiographed. Signals were quantified and normalized using the corresponding 18S rRNA signals to correct for uneven loading. Data are means \pm SE for 5 rats and are expressed as arbitrary units. Representative Northern blots are also shown. Statistical differences were assessed with ANOVA. $* P<0.05$ vs. PF rats. $C$ and $F$ : there is a negative correlation of muscle mass with USP19 mRNA expression in muscles from both Yoshida hepatoma- and Yoshida sarcoma-bearing rats. tion of proteins in the muscle. This would be similar to results of recent gene array studies that suggest that mRNA levels of USP14, which appears to recycle ubiquitin chains, also increases in several conditions of muscle wasting (21). Whether protein levels of USP14 change also remains unknown. Alternatively, USP19 may be involved in processing the polyprotein products of the ubiquitin genes to their mature forms. In either situation, the enzyme would be important in maintaining levels of free ubiquitin in the cell. One cannot rule out the additional possibility, though, that USP19 negatively regulates the ubiquitination and degradation of a specific protein that is essential for the muscle wasting process. However, this is the first demonstration of increased expression of a muscle deubiquitinating enzyme that does not associate with the proteasomelike USP14.

Consistent with a general role in muscle atrophy, USP19 was induced in all the catabolic conditions that we surveyed. It was also highly expressed in the testis, a tissue in which many proteins are being turned over during spermatid maturation. However, its expression was not tightly coordinated with the rates of muscle proteolysis. For example, its expression was lower in the slow-twitch oxidative soleus muscle compared with the fast-twitch glycolytic muscle (Fig. 2), although basal rates of proteolysis are higher in the former than in the latter (14). Furthermore, although expression increased upon fasting and in tumor-bearing animals, it did not return to basal levels upon 1 day of refeeding or in HWA448-treated tumor-bearing animals. In both of these latter conditions, rates of proteolysis appear to have normalized, although muscle mass remained significantly low $(1,17)$. In the case of refeeding, normaliza- tion of USP19 mRNA levels only occurred on day 2, when muscle mass had recuperated to control levels. Because mRNA levels for USP19 are inversely correlated with muscle mass (Figs. 4-7), USP19 may be involved in a function associated with regulation of muscle size or structure per se instead of proteolysis. In contrast, polyubiquitin expression correlates well with the rates of proteolysis in these and many other conditions. Thus USP19 mRNA levels may represent an index of muscle mass that could be useful in many pathological conditions, using small human muscle biopsies. The regulation of USP19 mRNA expression is likely to be controlled primarily by muscle intracellular factors, as increased expression was seen in a large number of diverse conditions whose pattern of humoral regulators is likely to be different in each condition.

USP19 may have a very specific function(s) in the muscle cell. In support of this, preliminary data indicate that small interfering RNA-mediated depletion of USP19 in cultured muscle cells does not alter steady-state levels of ubiquitinated proteins, suggesting that the enzyme has a limited number of specific substrates (O. A. J. Adegoke and S. S. Wing, unpublished observations). Indeed two isoforms of another deubiquitinating enzyme, USP2 (UBP45/UBP-t1 and UBP69/UBPt2), are expressed in muscle cells and are regulated during differentiation. They appear to have antagonistic effects on muscle cell differentiation in vitro (31). Also, our recent studies indicate that, in myoblasts, lowering intracellular USP19 levels results in arrest of cell growth (O. A. J. Adegoke and S. S. Wing, unpublished observations). Further studies to identify the specific substrates of USP19 will be required to 
define more precisely the functions of this enzyme and its role in muscle wasting.

\section{GRANTS}

This work was supported by Canadian Institutes of Health Research Grant MOP14700 (to S. S. Wing) and by research grants from the Association pour la Recherche sur le Cancer, the Institut National de la Recherche Agronomique, and Aventis Pharmaceuticals (to D. Attaix). O. A. J. Adegoke was supported by fellowships from the Canadian Diabetes Association and the McGill University Health Centre Research Institute. L. Combaret was supported by fellowships from the Association pour la Recherche sur le Cancer and the Canadian Diabetes Association. S. S. Wing is a recipient of a chercheurboursier salary award from the Fonds de la Recherche en Santé du Québec.

\section{REFERENCES}

1. Attaix D, Combaret L, Kee AJ, and Taillandier D. Mechanisms of ubiquitination and proteasome-dependent proteolysis in skeletal muscle In: Molecular Nutrition, edited by Zempleni J and Wallingford DH. Oxon, UK: CABI, 2003, p. 219-235.

2. Ausabel FM, Brent R, Kingston DD, Moore DD, Seidman JG, Smith JA, and Struhl K. Current Protocols in Molecular Biology. New York: Wiley, 1993

3. Balakirev MY, Tcherniuk SO, Jaquinod M, and Chroboczek J. Otubains: a new family of cysteine proteases in the ubiquitin pathway. EMBO Rep 4: 517-522, 2003.

4. Baracos VE, DeVivo C, Hoyle DH, and Goldberg AL. Activation of the ATP-ubiquitin-proteasome pathway in skeletal muscle of cachectic rats bearing a hepatoma. Am J Physiol Endocrinol Metab 268: E996-E1006, 1995.

5. Bodine SC, Latres E, Baumhueter S, Lai VK, Nunez L, Clarke BA, Poueymirou WT, Panaro FJ, Na E, Dharmarajan K, Pan ZQ, Valenzuela DM, DeChiara TM, Stitt TN, Yancopoulos GD, and Glass DJ. Identification of ubiquitin ligases required for skeletal muscle atrophy. Science 294: 1704-1708, 2001.

6. Chen X, Zhang B, and Fischer JA. A specific protein substrate for a deubiquitinating enzyme: liquid facets is the substrate of Fat facets. Genes Dev 16: 289-294, 2002.

7. Chomczynski $\mathbf{P}$ and Sacchi N. Single-step method of RNA isolation by acid guanidinium thiocyanate-phenol-chloroform extraction. Anal Biochem 162: 156-159, 1987.

8. Chung CH and Baek SH. Deubiquitinating enzymes: their diversity and emerging roles. Biochem Biophys Res Commun 266: 633-640, 1999.

9. Combaret L, Tilignac T, Claustre A, Voisin L, Taillandier D, Obled C, Tanaka K, and Attaix D. Torbafylline (HWA 448) inhibits enhanced skeletal muscle ubiquitin-proteasome-dependent proteolysis in cancer and septic rats. Biochem J 361: 185-192, 2002.

10. Curcio-Morelli C, Zavacki AM, Christofollete M, Gereben B, de Freitas BC, Harney JW, Li Z, Wu G, and Bianco AC. Deubiquitination of type 2 iodothyronine deiodinase by von Hippel-Lindau protein-interacting deubiquitinating enzymes regulates thyroid hormone activation. $J$ Clin Invest 112: 189-196, 2003.

11. Dardevet D, Sornet C, Taillandier D, Savary I, Attaix D, and Grizard J. Sensitivity and protein turnover response to glucocorticoids are different in skeletal muscle from adult and old rats-lack of regulation of the ubiquitin-proteasome proteolytic pathway in aging. J Clin Invest 96: 2113-2119, 1995.

12. Frohman MA, Dush MK, and Martin GR. Rapid production of fulllength cDNAs from rare transcripts: amplification using a single genespecific oligonucleotide primer. Proc Natl Acad Sci USA 85: 8998-9002, 1988.

13. Glickman $\mathbf{M H}$ and Ciechanover A. The ubiquitin-proteasome proteolytic pathway: destruction for the sake of construction. Physiol Rev 82: 373-428, 2002.

14. Goldberg AL. Protein synthesis in tonic and phasic skeletal muscles. Nature 216: 1219-1220, 1967.

15. Gomes MD, Lecker SH, Jagoe RT, Navon A, and Goldberg AL. Atrogin-1, a muscle-specific F-box protein highly expressed during muscle atrophy. Proc Natl Acad Sci USA 98: 14440-14445, 2001.

16. Jagoe RT and Goldberg AL. What do we really know about the ubiquitin-proteasome pathway in muscle atrophy? Curr Opin Clin Nutr Metab Care 4: 183-190, 2001.

17. Kee AJ, Combaret L, Tilignac T, Souweine B, Aurousseau E, Dalle M, Taillandier D, and Attaix D. Ubiquitin-proteasome-dependent muscle proteolysis responds slowly to insulin release and refeeding in starved rats. J Physiol 546: 765-776, 2003.

18. Kim JH, Park KC, Chung SS, Bang O, and Chung CH. Deubiquitinating enzymes as cellular regulators. J Biochem (Tokyo) 134: 9-18, 2003.

19. Lam YA, Xu W, DeMartino GN, and Cohen RE. Editing of ubiquitin conjugates by an isopeptidase in the $26 \mathrm{~S}$ proteasome. Nature 385 : 737 740, 1997.

20. Lecker SH. Ubiquitin-protein ligases in muscle wasting: multiple parallel pathways? Curr Opin Clin Nutr Metab Care 6: 271-275, 2003.

21. Lecker SH, Jagoe RT, Gilbert A, Gomes M, Baracos V, Bailey J, Price SR, Mitch WE, and Goldberg AL. Multiple types of skeletal muscle atrophy involve a common program of changes in gene expression. FASEB J 18: 39-51, 2004.

22. Lecker SH, Solomon V, Mitch WE, and Goldberg AL. Muscle protein breakdown and the critical role of the ubiquitin-proteasome pathway in normal and disease states. $J$ Nutr 129: 227S-237S, 1999.

23. Lecker SH, Solomon V, Price SR, Kwon YT, Mitch WE, and Goldberg AL. Ubiquitin conjugation by the N-end rule pathway and mRNAs for its components increase in muscles of diabetic rats. J Clin Invest 104: 1411-1420, 1999.

24. Leggett DS, Hanna J, Borodovsky A, Crosas B, Schmidt M, Baker RT, Walz T, Ploegh HL, and Finley D. Multiple associated proteins regulate proteasome structure and function. Mol Cell 10: 495-507, 2002.

25. Li M, Chen D, Shiloh A, Luo J, Nikolaev AY, Qin J, and Gu W. Deubiquitination of p53 by HAUSP is an important pathway for p53 stabilization. Nature 416: 648-653, 2002.

26. Li YP, Chen Y, Li AS, and Reid MB. Hydrogen peroxide stimulates ubiquitin-conjugating activity and expression of genes for specific E2 and E3 proteins in skeletal muscle myotubes. Am J Physiol Cell Physiol 285: C806-C812, 2003.

27. Li YP, Lecker SH, Chen Y, Waddell ID, Goldberg AL, and Reid MB. TNF- $\alpha$ increases ubiquitin-conjugating activity in skeletal muscle by up-regulating UbcH2/E220k. FASEB J 17: 1048-1057, 2003.

28. Mitch WE and Price SR. Mechanisms activating proteolysis to cause muscle atrophy in catabolic conditions. J Ren Nutr 13: 149-152, 2003.

29. Ozkaynak E, Finley D, Solomon MJ, and Varshavsky A. The yeast ubiquitin genes: a family of natural gene fusions. EMBO J 6: 1429-1439, 1987.

30. Pantaleon M, Kanai-Azuma M, Mattick JS, Kaibuchi K, Kaye PL, and Wood SA. FAM deubiquitylating enzyme is essential for preimplantation mouse embryo development. Mech Dev 109: 151-160, 2001.

31. Park KC, Kim JH, Choi EJ, Min SW, Rhee S, Baek SH, Chung SS, Bang O, Park D, Chiba T, Tanaka K, and Chung CH. Antagonistic regulation of myogenesis by two deubiquitinating enzymes, UBP45 and UBP69. Proc Natl Acad Sci USA 99: 9733-9738, 2002.

32. Pickart CM. Mechanisms underlying ubiquitination. Аnпи Rev Biochem 70: 503-533, 2001.

33. Temparis S, Asensi M, Taillandier D, Aurousseau E, Larbaud D, Obled A, Bechet D, Ferrara M, Estrela JM, and Attaix D. Increased ATP-ubiquitin-dependent proteolysis in skeletal muscles of tumor-bearing rats. Cancer Res 54: 5568-5573, 1994.

34. Tiao G, Fagan J, Roegner V, Lieberman M, Wang JJ, Fischer JE, and Hasselgren PO. Energy-ubiquitin-dependent muscle proteolysis during sepsis in rats is regulated by glucocorticoids. J Clin Invest 97: 339-348, 1996.

35. Tisdale MJ. Cachexia in cancer patients. Nat Rev Cancer 2: 862-871, 2002.

36. Verma R, Aravind L, Oania R, McDonald WH, Yates JR III, Koonin EV, and Deshaies RJ. Role of Rpn11 metalloprotease in deubiquitination and degradation by the 26S proteasome. Science 298: 611-615, 2002.

37. Wilkinson KD. Regulation of ubiquitin-dependent processes by deubiquitinating enzymes. FASEB $J$ 11: 1245-1256, 1997.

38. Wing SS. Deubiquitinating enzymes - the importance of driving in reverse along the ubiquitin-proteasome pathway. Int J Biochem Cell Biol 35: 590-605, 2003.

39. Wing SS, Haas AL, and Goldberg AL. Increase in ubiquitin-protein conjugates concomitant with the increase in proteolysis in rat skeletal muscle during starvation and denervation atrophy. Biochem J 307: 639645, 1995.

40. Wray CJ, Mammen JM, Hershko DD, and Hasselgren PO. Sepsis upregulates the gene expression of multiple ubiquitin ligases in skeletal muscle. Int J Biochem Cell Biol 35: 698-705, 2003. 